\title{
Playing with genetic and epigenetic concepts at the school: an Epigenetic Orchestra project
}

\author{
Conchita Alonso $^{1 *}$ (D) and Yolanda Palomares ${ }^{2}$
}

\begin{abstract}
A sound biological education at early schooling stages is highly desirable for individual understanding of the nature of science and comprehension of evolutionary theory. Making accessible the concepts to young minds is notwithstanding key and playful learning linked to artistic projects can be useful to reach this goal. Here, we propose a set of activities structured into three units that can be developed at school. They use music as a playful learning tool to support students' motivation to discover the building blocks of genetic code, genetic variation and epigenetic regulation. Familiarity with these core molecular concepts will smooth their future understanding of the evolutionary process. A final activity programmed for a general audience can also contribute to better value scientific knowledge among the local population. And, it will potentially inspire some young girls and boys in orienting their future career development towards science.
\end{abstract}

Keywords: Epigenetics, Ludic learning, Molecular genetics, Music, Science education

\section{Introduction}

As the basis of all living organisms, genetic code bears the information by which any biological process ultimately functions and evolves. Theory for evolutionary genetics is rich (Felsenstein 2019) and methodology for genetic analyses has revolutionized during the last 50 years (Allendorf 2017). An understanding of basic genetics is essential for anyone hoping to understand more than the superficial aspects and processes of biology and evolution, including heredity and phenotypic variability within species, long-term relatedness across species, or the ability of certain individuals to colonize and invade new environments and the challenges that this impose to human wealth (Kokko et al. 2017). Whilst genetics does already have a place in a student's

\footnotetext{
*Correspondence: conalo@ebd.csic.es

1 Estación Biológica de Doñana, CSIC, Avenida Américo Vespucio 26, 41092 Seville, Spain

Full list of author information is available at the end of the article
}

biological education, its introduction doesn't occur until the later school years and frequently out of the obligatory curriculum. Epigenetics represents a slightly more complex aspect of the genome features, that goes almost entirely untaught in most school curricula. Indeed, the field of epigenetics may not be introduced until a student is years into a university-level education in biology (see e.g., GENIE 2020). Evidence gathered during the last decades suggests that epigenetics, the presence of chemical tags attached to DNA and surrounding proteins, is an incredibly important aspect of genomes and their translation into the observed phenotypes, which explains why identical clonal individuals can look like different when grown under contrasting environments and how their descendants may survive better under similar environmental challenges. Epigenetics may, therefore, account for some phenomena that cannot be fully explained by classic genetics and Darwinian evolution based on random and infrequent mutation (Jablonka 2017). Such phenomena include 
plasticity, aging, or the ability to overcome stress and disease in both plants and animals after recurrent exposure (Hilker et al. 2016; Auge et al. 2017). Its relevance for human health has placed the topic on the front page of broad audience magazines and become the core of successful popular science books (Fig. 1; Carey 2012), suggesting it is now the time for improving its formal scholarship. We believe that learning about genetic code and epigenetic regulation is appropriate for students of a school age. Make it accessible and amusing will certainly contribute to develop a coherent view of scientific knowledge (Bloom and Weisberg 2007) and pave the way to understand evolution (Mead et al. 2017).

Making advanced concepts accessible is a challenge that any learning establishment faces and, as such, a variety of different techniques have been developed by pedagogues. One of these methods involves the introduction of familiar concepts as metaphors and/ or analogies for more complex concepts (Woody and Himelblau 2013). This method allows students to grasp new and difficult concepts in the context of other more familiar ideas and, thus, it facilitates a meaningful understanding that might not be possible otherwise. Music provides an informal, pleasing and dynamic

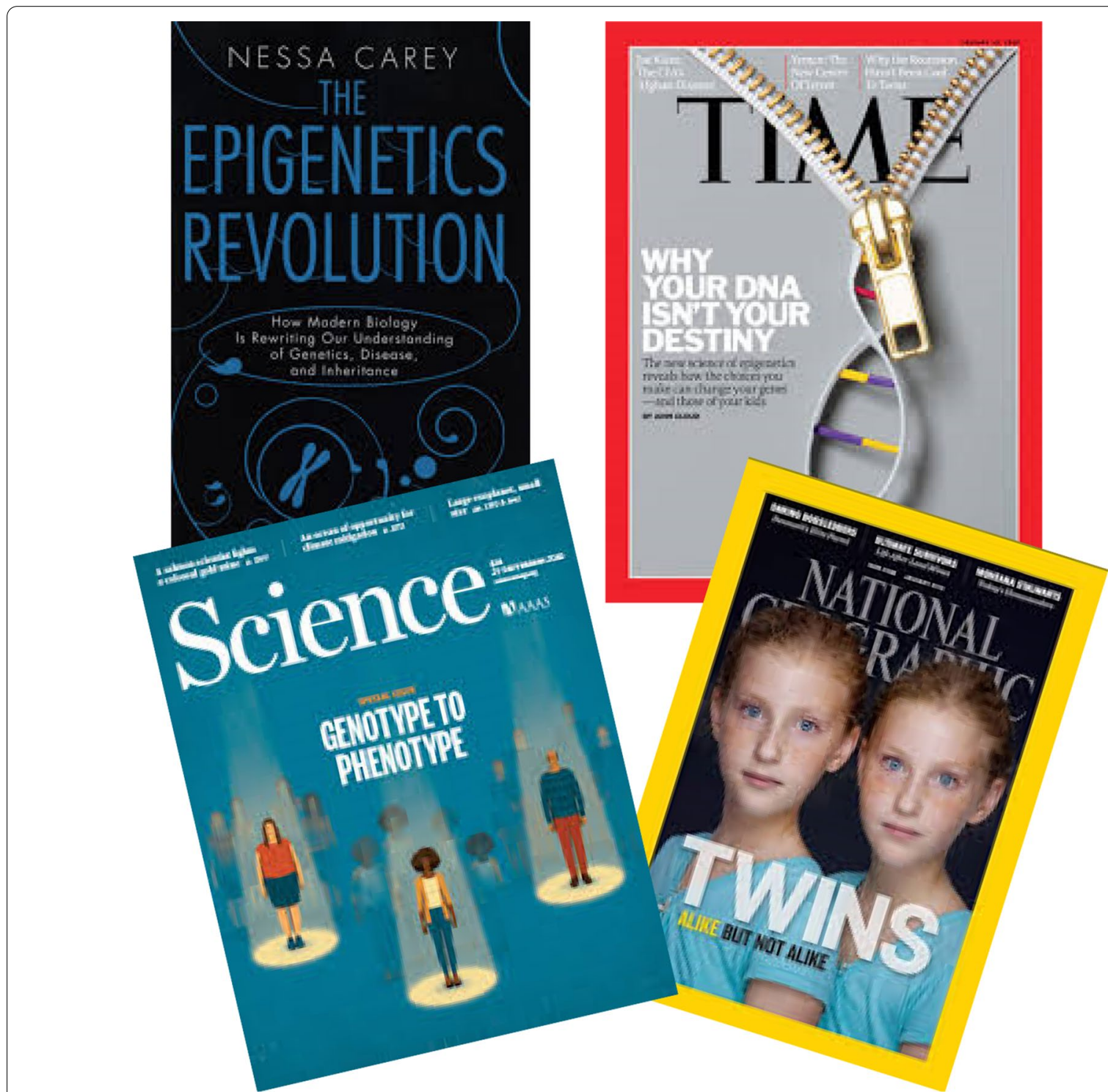

Fig. 1 Some of the front pages devoted to epigenetics in the last two decades by broad audience journals and popular science books (e.g., Carey 2012) 
environment and an outstanding teaching tool that can be used in the classroom and outdoors to improve student's individual talents such as concentration, creativity, rhythm, and coordination, as well as for training their team building capacities (Hallam 2010). Music is also an art taught throughout primary school in many countries, and often into further education. Therefore, the basis of music language and the concept of notes, sheet music, orchestra, etc. are familiar to children due to this constant exposure. The association between colours and notes, as already developed by e.g. school xylophones and boomwhakers (West Music 2020), can also be established to reinforce the learning with a visually appealing dimension.

We propose here a set of activities that use music as a ludic learning tool (Fredrickson and Branigan 2005), i.e. methodology that promotes playful actions and positive emotions when teaching, to support students' learning and motivation to understand the building blocks of genetic code, genetic variation, and epigenetic regulation as the initial molecular understanding required for future study of evolutionary processes. We will establish equivalences between some familiar concepts in music language and the unfamiliar and more specific concepts in genetics and epigenetics. The ultimate function of both as information codes lends them intrinsic value as representations of each other, smoothing meaningful understanding of the most complex concepts for small children ( $8-12$ years) and a general audience. Teaching concepts of genetics and epigenetics at a younger age to students, coupled with the potential of music as a teaching tool of these fields, creates an excellent opportunity to enhance the biological education in elementary and secondary schools. An earlier familiarity with these fields would help provide the context for future biological education, and help students advance within the fields of molecular and evolutionary biology at a far quicker pace (Mead et al. 2017).

In the following sections we detail the content of units and activities and how musical theory and practice can be used on each one to add a ludic element within student's education process while promoting critical thinking. Units can be used as supporting tools within class, in summer schools and extra-curricular activities, or in outreach events such as the European Researchers' Night (MSCA-NIGHT 2020) aiming to strengthen society education in Science. The instructor might need to tune the content to the age and prior knowledge of the target group. Developing the activities as a transdisciplinary project together with music or art teachers could be particularly fruitful.

\section{Materials and methods \\ Rationale}

The rationale behind this practice holds that musical notes are similar conceptually to genetic bases. Each note means little if considered alone, but in sequence they form a coherent code that can instruct the production of a melody/song in the case of the instrument, or the "instructions" for cellular functions in the case of the genetic code. Additionally, parallels can be drawn between musical note alterations (e.g., length, sustain, bemolle...) and epigenetic marks (e.g., DNA cytosine methylation). The multicellular organism can be envisaged as an orchestra, in which different music sheets are provided for each group of instruments (i.e., cell and tissue differentiation), and the silencing of certain musical instrument illustrates the gene "silencing" effect of DNA cytosine methylation at gene promoters. Finally, the environment external to the organism can be described as having the same role as the conductor within an orchestra. Instruments follow the conductor's instructions to produce the expected music, and cells, tissues, and individuals follow epigenetic regulation to suit the conditions settled by different environments. Along the whole process, a playful environment and the use of music intends to generate positive emotions that favour the learning process (Fredrickson and Branigan 2005; Hallam 2010).

\section{Structure}

We propose three units that can be developed sequentially. The basic genetic code activity described in Unit 1 is designed to be accessible to primary-aged students and above, whilst Units 2-3 may be best suited for more advanced students, as a first step towards their learning about evolution. Alternatively, they can be developed by different groups of students, with a final activity for sharing the learning process and outcomes of each Unit task. The activity can start by asking the student what they know about genetics, why they look similar to their relatives, and if they have ever heard of genes, genetics and epigenetics.

Unit 1: Introduction to the genetic code ( $\mathrm{k} 8-\mathrm{k} 12)$.

This unit draws a parallel between genetic bases, colours and musical notes as different information codes.

Unit 2: Epigenetic regulation as the operator of genetic information (k10-k16).

This unit draws a parallel between functional genetic sequences and sheet music or song, as both establish a coherent assembly of code by using alterations. 
Unit 3: The orchestra: a unique code for multiple cell types and environments (k10-k16).

This unit draws a parallel between a complex organism and an orchestra, with coordinated information for different cell types and instruments. Relevance of the environment as the conductor for fine-tuning the orchestra's performance will be highlighted.

In the following paragraphs we describe the materials required and suitable methodology for the teacher to lead the learning process.

\section{Unit1-Introduction of genetic code Goals}

Getting familiar with the concepts of information units and code, the four DNA nitrogen bases and genetic code. The activity will help students understand that codes are ubiquitous in our world: traffic lights, Morse code, Braille, abecedarian, music notes... DNA is just another code: the code of Life. The outcome of this activity will be a familiarity with DNA, its basic structure of four nitrogen bases and two complementary chains, as a solid basis for future molecular biology education. The concepts of mutation and genetic variability will also be made accessible.

\section{Materials}

- Musical instruments with different sound and colour. Ideally, coloured boomwhackers or xylophones. Alternatively, four home-made devices such as bottles, cans or glasses containing different amounts of water that will produce different sounds.

- Coloured papers.

- Coloured modelling clay and tooth picks.

\section{Development}

The first part of the activity will be the introduction of code as an abstract yet ubiquitous concept. The teacher will begin by explaining code is any convention based on a limited list of information bits that combined are suitable to transmit a large amount information quickly and reliably. Teacher will then proceed by naming some examples: abecedarian letters, numbers, Morse code, smoke signals, etc. The children will then try and name as many as possible, before the teacher introduces DNA as a code with four basic units.
Using a coloured diagram, the children will be introduced to the four nitrogen bases: Adenine, Thymine, Guanine and Cytosine (Fig. 2). The four colours and four musical notes (=instruments) will be associated with them henceforth obtaining a visual and acoustic representation of DNA bases, suitable for building a genetic sequence. The metaphor of notes as bases will be established by asking children to hit single notes on the respective instruments. Using the coloured papers, they will learn the difference between purines (A, G) and pyrimidines $(\mathrm{C}, \mathrm{T})$ by drawing them. Each pupil will select a colour and draw the outline of one base, then the classroom will have a good opportunity to build different sequences by ligating their charts in different orders. Next, the teacher will ask them to make groups and form chains, someone will write the sequences on the board. Children should reshuffle and write down the new chains to play with the concept of genetic variability. The concept of mutation can be introduced as any error in the expected colour-shape association.

The activity can proceed showing that the bases are connected to each other by sugar and phosphate groups forming a chain whose length is highly variable across species. The DNA molecule has two complementary chains and the four bases are always linked across the two chains in two specific pairs: Adenine is bonded with Thymine and Cytosine is bonded with Guanine. The two chains are shaped like a twisted ladder. Learning will be reinforced with a small task in which the children either individually or in small groups make a small part of genetic code using coloured paper balls glued on a sheet, and aligning bases correctly in two chains. Again, the concept of mutation can be introduced as any error in this pattern that contributes to genetic variability. The teacher will ensure that the children understand the basic structure of DNA before moving on.

\section{Final activity}

Playing with the concepts learned. Once the concepts of information bits and codes, and the metaphor of notes as bases are established, it is time to experience how the genetic code of any individual is the repetition of these bits in a certain unique order. Children can be split into groups for writing small melodies ( 15-20 notes) that will perform accordingly using the musical instruments. Once each group produces their small melody the teacher will ask them to assemble the same melody in the form of genetic code (= single chain). The multiple ways used to identify the bases (colour, shape, sound, letter) could help students with different talents to conceptualize and retain the notion of genetic code. The next step will be to produce the complementary chain, as mentioned above, the small 

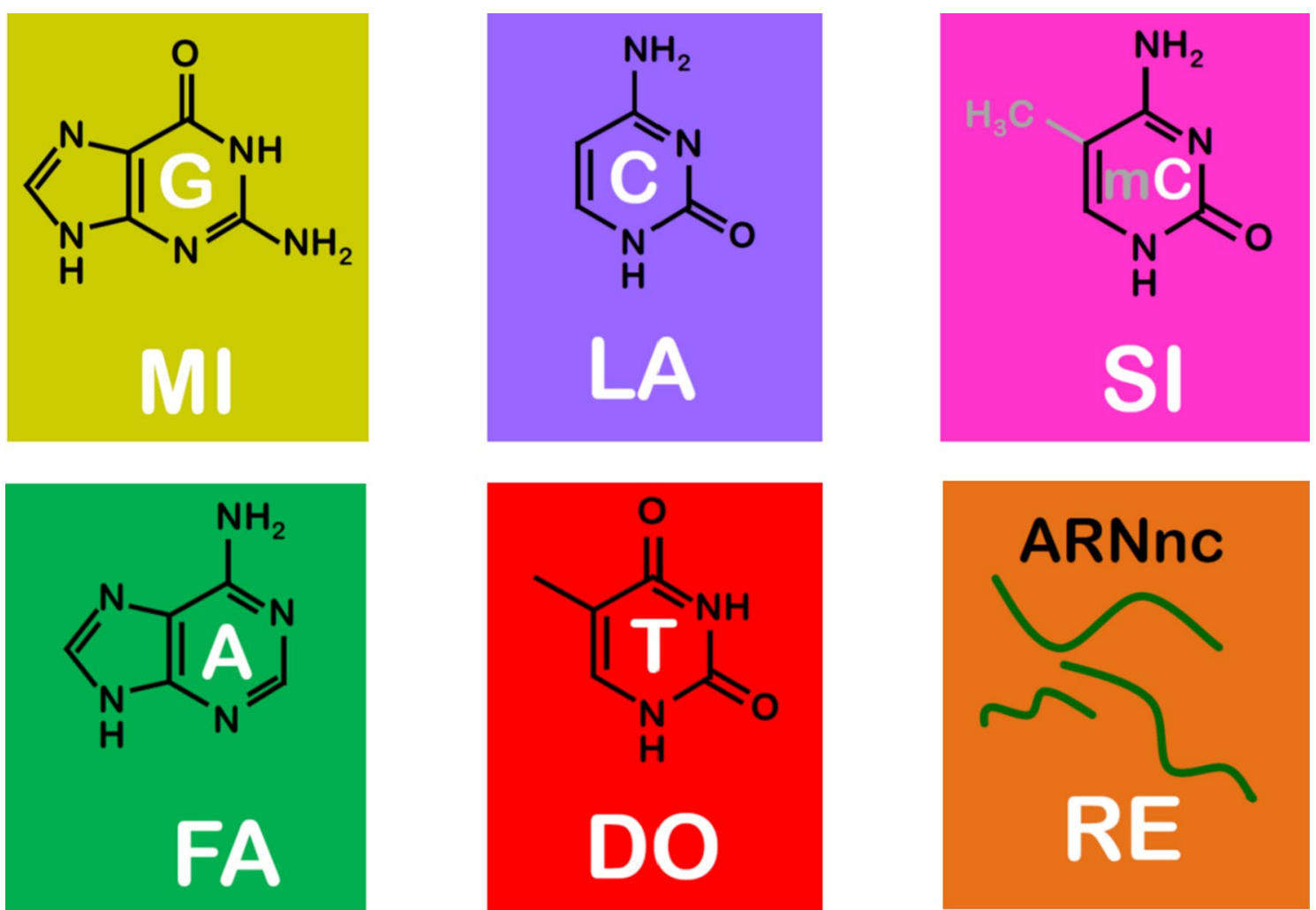

Fig. 2 Example of coloured diagrams suitable for establishing the parallels between DNA bases, music notes and colours that will be used in the project. In addition to the four nitrogen bases useful for Unit 1: green Adenine (FA), red Thymine (DO), yellow Guanine (MI) and purple Cytosine (LA). Two epigenetic marks: pink 5-methyl-Cytosine (SI) and orange small non-coding RNAs (RE) useful for Unit 2 are shown

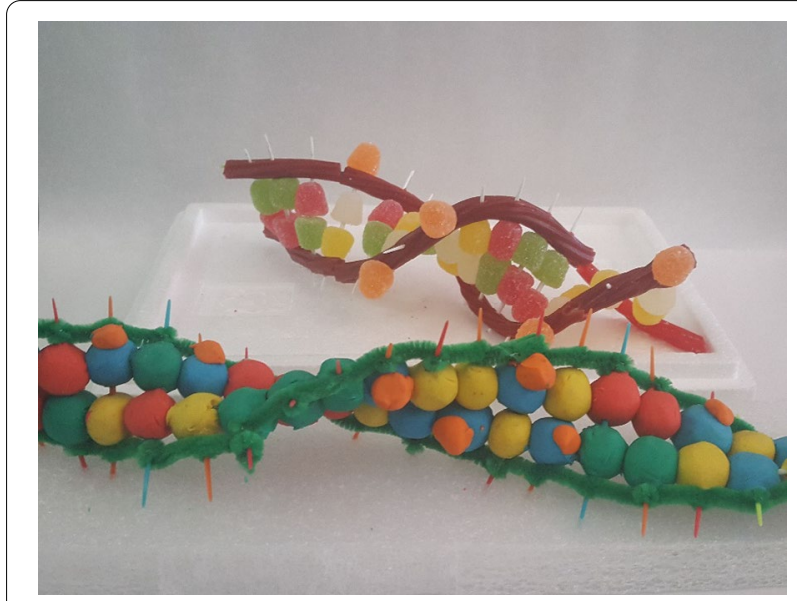

Fig. 3 Examples of 3D prototypes of double-helix DNA made with Plasticidine and sweets. Note the presence of a few orange balls /sweets external to the double-helix and always associated to the Cytosine (blue Plasticidine balls, white sweets) to symbolize methylations (Courtesy of Monica Medrano and María Teresa Boquete) children can construct the code using a template for a complementary double chain gluing coloured paper balls. Older students can be challenged to produce 3D double helix models with modelling clay balls linked with tooth picks that can be used for a public exhibition (Fig. 3). By assembling all group melodies, the class will build a longer song that can be performed with the boomwhackers, xylophones, sweet flutes or any other instrument they can play.

\section{Evaluation}

Students will be asked to propose a list of questions about the concepts they have learned, particularly those that were new and they think other children from a class that has not made the practice yet will fail in answering. This information will be collected to develop multiplechoice tests (i.e., concept inventories; Furrow and Hsu 2019) that examine the learning process and post-activity student conceptual understanding of a set of basic genetics concepts as the ones highlighted in bold in the Unit description above: genetic code, nitrogen base, complementary chains of DNA, mutation, genetic variability. 


\section{Unit 2-Epigenetic regulation as the operator of genetic information Goals}

Getting familiar with the concepts of epigenetic regulation and the main types of epigenetic marks. The activity will help students understand that bases and genetic code can be altered by several epigenetic mechanisms such a DNA methylation, as individual notes are altered in sheet music, causing them to act/sound differently without modifying the sequence. The concept of phenotype, i.e. the multiple characteristics of an organism and its parts that can be measured such as individual size, leaf shape, flower colour, nectar sugar content, etc., will be introduced as the result of an interaction between genotype (i.e., the full genetic code of an individual) and environment, and the actions of epigenetic regulation.

\section{Materials}

Same as used in Unit 1. We just need 1-2 extra colours and instruments.

\section{Development}

Sound alterations and accidentals such as tempo, sustain/bemolle, ligation, silences... are important in creating complex music codes and beautiful songs. By adding these alterations to musical notes, full sheet music is produced that can be interpreted by different players to reproduce the intended sound. The fifth base: 5-methylCytosine $(\mathrm{mC})$ will be presented as a key epigenetic factor, and a different colour and sound will be associated to it. The $\mathrm{mC}$ will be introduced into the music codes / DNA molecules developed in the Unit 1. A small frequency of them will be enough to resemble the natural facts. Methylated Cytosines are $<5 \%$ of all Cytosines in human genomes but up to $40 \%$ in some plant species (Alonso et al. 2019). Depending on students' age, relevance of Methyl groups $\left(\mathrm{CH}_{3}\right)$ to switch on/off the activity of different molecules, and particularly DNA Cytosines and gene expression, will be explained. The analogy between gene expression and sound level can be established. Small RNAs, histone tail modifications, and/ or chromatin compaction could be further introduced at High School levels.

\section{Final activity}

A music sheet of a well-known song will be provided without title. The analogy between notes and the five bases (six or seven if small RNAs and histone modifications have been explained) will be established and tubes/ instruments assigned. All notes will be initially played at equal length, ignoring silences and any other tempo indication. Students will try to guess the song. In a second step, students should try to play the real music sheet with all alterations noted and repeat the guessing trial. All the options performed will be considered different phenotypes. An illustration of phenotypic variance within a certain species can be provided through pictures or by becoming conscious of the variance in body features the group of students encompasses.

\section{Evaluation}

Students can be asked to propose a list of questions about the new concepts they have learned to further develop the genetic concept inventory initiated at Unit 1 to include a set of relevant concepts of genetics and epigenetics such as DNA methylation, gene expression, epigenetic regulation, and individual genotype and phenotype.

\section{Unit 3-The epigenetic orchestra: a unique code for multiple cell types and environments \\ Goal}

Getting familiar with the complexity of multicellular organisms in which a single genetic code produces different cell types and tissues, that will be epigenetically altered during development and aging. Learn that epigenetic regulation coordinates cell differentiation and conditions some individual responses to environmental stress or disease challenge.

\section{Materials \\ Different instruments to perform ensemble.}

\section{Development}

Using a diagram of a plant and the music sheets for different instruments performing the same piece, the teacher will explain how each instrument is representative of specific tissues, e.g. roots $=$ piano, stems $=$ drum set, leaves $=$ violins, flowers $=$ flutes (Fig. 4). All instruments together will produce the music and different alterations are needed on each music sheet to ensemble the respective sounds. Similarly, epigenetics modulates the action of every cell and organ to build an integrated individual. The activity will develop by each instrument playing first alone, then together in order to experience the difference. If playing different instruments is limiting a choral version using pupil's voices can be used instead.

The next step will be to establish the parallelism between the conductor of the orchestra and the environment's role in dictating how different tissues in a complex organism should join and properly coordinate for tailoring their activity and producing a certain phenotype. Depending on the environmental conditions a plant experiences (e.g., drought, contamination, heat stress, nutrient scarcity, herbivory) it will respond differently, for instance delaying or advancing flowering, 


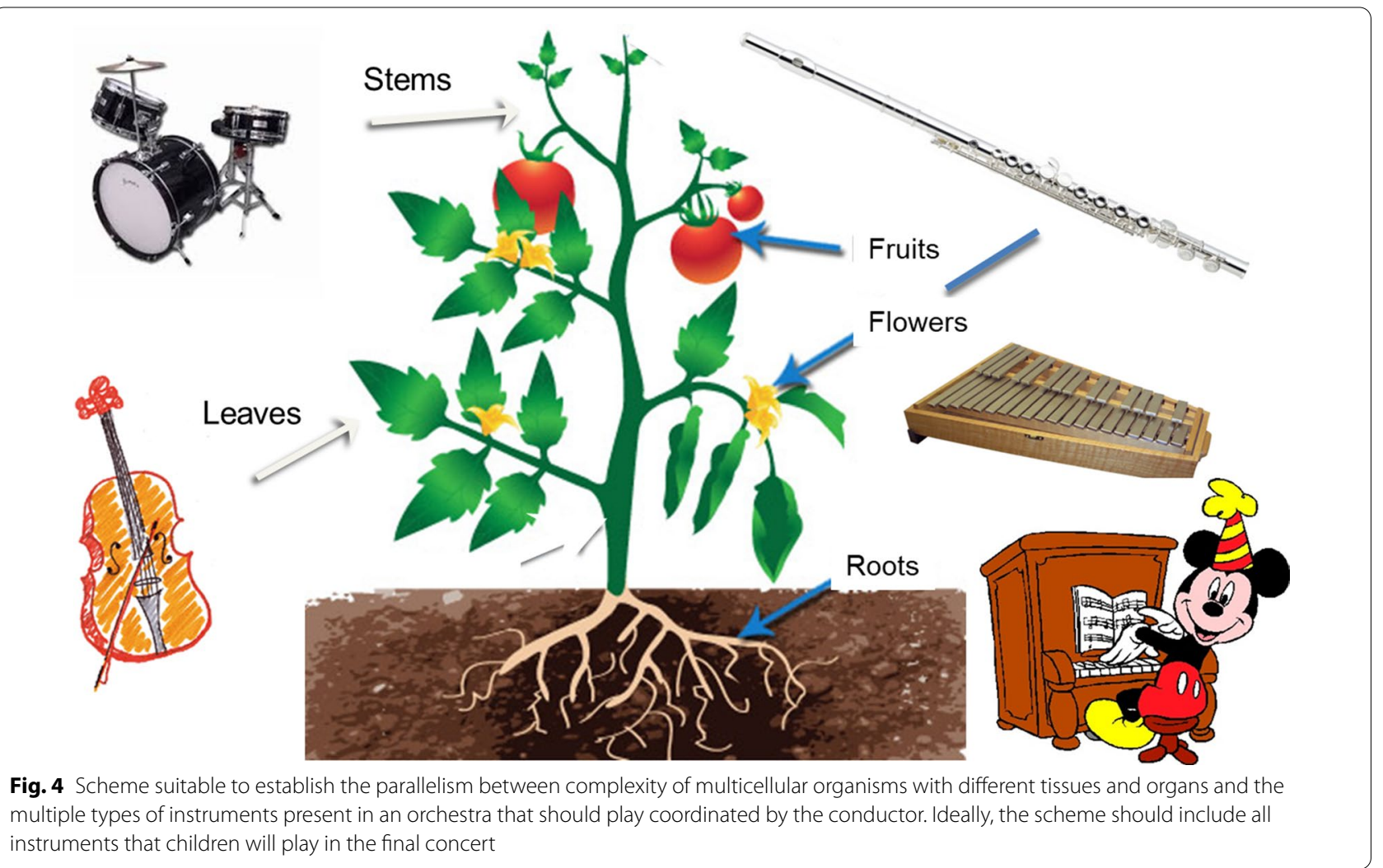

producing bigger or smaller leaves, increasing the number of spines..., just as the different instruments will play faster, stronger, or milder depending on the conductor's indications.

Illustration of such coordinated responses can be achieved or reinforced through pictures or a practical project where plants are grown in very contrasting conditions (e.g., lentils grown in sunny vs. highly shaded locations). The classical peloric flowers, mature green tomatoes, or prickly leaves of the holly tree (Fig. 5) can be used to exemplify some of the most striking phenotypic changes associated with epigenetic shifts (see Jablonka and Raz 2009 for a list of examples).

\section{Final activity}

Students will be challenged to develop the script for developing a concert that illustrates the acquired knowledge of all three Units. A slide presentation with the questions outlined after Unit 1 and 2 can be used for structuring the performance. The performance will be programmed as an after-school activity suitable for sharing the learning process with their school mates and families. Teacher will assist in suggesting illustrations, music, games, costumes... and encouraging the rehearsal for a successful and ludic experience.

\section{Evaluation}

Students should answer a questionnaire to assess their learning, and their attitude towards scientific arguments based on hypothesis proposal and evidence gaining. Their potential involvement in future activities to learn more about evolutionary change can also be assessed.

\section{Results and discussion}

Music provides a useful analogy to help young students to grasp unfamiliar concepts of genetics that would pave the way to understanding the principles of evolution at a later stage (Puig and Jiménez-Aleixandre 2011, Woody and Himelblau 2013; Mead et al. 2017). A playful environment should further contribute to generate positive emotions in children, which may play a significant role as a driving force for curiosity and self-learning about the topic, and reinforce retaining the acquired knowledge (Nicolaou et al. 2015). The complexity of the topic, time availability within the programmed course and familiarity with the music language can be crucial for the success of the activity, therefore, engaging music or art teachers into a transdisciplinary project could be particularly fruitful. The epigenetic orchestra project has been developed for several years as an extracurricular activity to enrich music and scientific knowledge in elementary 

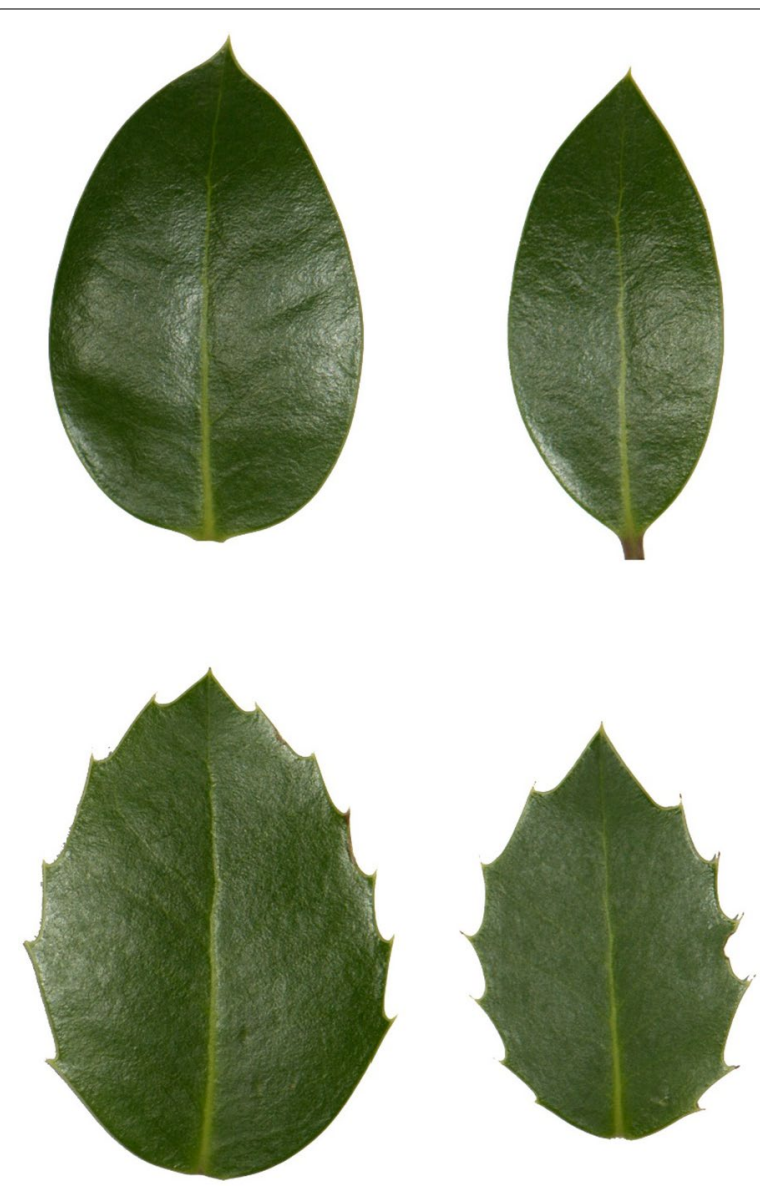

Fig. 5 Example of external characters that vary according to changes in epigenetic marks. In this picture we see adjacent prickly and non-prickly leaves that grew along the same branch of holly trees (Ilex aquifolium) and differed in the frequency of 5-methyl-Cytosines at certain positions of their genetic sequence (Herrera and Bazaga 2013). Image courtesy of Carlos M. Herrera

school children (8-12 years) and help them to better recognize and value the advances and contributions of scientists to society.

The Units proposed here have been elaborated to transfer our successful experience with students of two Elementary Music Schools in Sevilla district (Spain), which evolved from small concerts to families within each School to a couple of open performances conducted at the European Researchers' Night in 2017 and the Science House Museum of Sevilla in 2018 (see http://www.flaut alibre.com/category/epigenetica/ for details of performed activities). In this final activity students become teachers for a general audience and efficiently spread a basic but sound knowledge on genetics and epigenetics and hopefully contribute to better value Science as an essential element of society's culture. The experience was very positively evaluated by the students and their families, as well as by the organizers. We feel the Units here proposed can be inspiring for both teachers and researchers aiming to contribute to society education in Science through Art, pursued by International Calls such as the European Researchers' Night (MSCA-NIGHT 2020), the National Science Week (e.g., Madrid Science Week 2019, Australia Science Week 2020, British Science Week 2020) and other local Science Festivals (e.g., Feria de la Ciencia 2020). In the following paragraphs we will discuss further the knowledge that can be included in each Unit depending on the age and previous knowledge of the students, and will provide some references and online resources available for teachers who might engage on the idea.

The classical examples of green/yellow peas or pink/ white flowers can be explained at Unit 1 to further illustrate how information stored within genetic codes is transferred into cell and individual's differential traits (i.e., phenotype) that can be linked to specific locations of the DNA molecule (see https://teach.genetics.utah. edu/ for very useful tools materials; Homburger et al. 2019). Continuing with some historical background, the relevance of Rosalind Franklin's contribution for the discovery of DNA structure can be also introduced at Unit 1 (see e.g., http://dnaftb.org/19/bio-3.html). Finally, parallels between computer systems and DNA storage capacities can be exposed to highlight the outstanding capacity of DNA structure for storing and faithfully transmitting information (see e.g., Erlich and Zielinski 2017).

In activities programmed for several weeks or as a team project for students at secondary school, a full description of how genetic information is assembled into genes and stored within each cell nucleus, including the arrangement of the DNA molecule around histone proteins, chromatin compaction and chromosome formation can be explained at Units 2 or 3 (see e.g., https://kids.kiddle.co/Chromosome). Also, the contribution of Barbara McClintock's research for the discovery of transposable elements in maize (http://dnaftb.org/32/index.html) can be introduced. All these topics will enrich the concept inventory developed through this activity.

\section{Conclusion}

We are convinced that Arts are best suited to engage young students fostering their curiosity, interest and knowledge about Biology and Evolution. We present here three Units for introducing genetic and epigenetic concepts to elementary and secondary school children playing with music, that will pave the way for their future learning about molecular and evolutionary biology. Whilst there are many potential approaches to teaching such concepts, using a heavily familiar art such as music as an analogy has great potential. Paying special attention 
to the contribution of research conducted by women in this field might strengthen the way young girls and students from other marginalized groups see themselves in relation to the world of science. A final activity programmed for a general audience will further contribute to improve the level of scientific knowledge among the population and will potentially offer an extra reward for the students most involved in the project development. Such a ludic learning experience might be inspiring for some young girls and boys in orienting their future career development towards Science.

\begin{abstract}
Acknowledgements
CA dedicates this paper to her children Clara and Nicolás who inspired the launch of this project. Special thanks to Nico Varo for his continuous support and to Carlos M. Herrera, Mónica Medrano and all present and past members of the Lab for insightful discussion and suggestions. We thank Alexander Morgan and Jonathon Roberts for their input with the language at different writing stages and two anonymous referees for their constructive comments. We are especially indebted to all the students of the Elementary Music Schools of Triana and América Martínez who played with us in the Epigenetic Orchestra in 2016-2018 and their families.
\end{abstract}

\section{Authors' contributions}

The two authors developed the ideas and conducted the project. CA drafted the manuscript. Both authors read and approved the final manuscript.

\section{Funding}

Funding was provided by ESEB outreach initiative (2016 call), the Spanish Ministerio de Economía y Competitividad (Projects CGL2016-76605-P, PID2019-104365 GB-I00), the European Commission Marie Sklodowska-Curie ETN 'EpiDiverse' (MSCA-ITN-2016-764965) and CSIC Open Access Publication Support Initiative (Unit of Information Resources for Research).

\section{Availability of data and materials}

No further data or materials exist.

\section{Declarations}

\section{Competing interests}

Authors declare no competing interests.

\section{Author details}

'Estación Biológica de Doñana, CSIC, Avenida Américo Vespucio 26, 41092 Seville, Spain. ${ }^{2}$ Conservatorio Elemental de Música "América Martínez", Plaza Rolando Campos s/n, Mairena del Aljarafe, 41927 Seville, Spain.

Received: 22 September 2020 Accepted: 7 May 2021

Published online: 25 May 2021

\section{References}

Allendorf FW. Genetics and the conservation of natural populations: allozymes to genomes. Mol Ecol. 2017;26:420-30. https://doi.org/10.1111/mec. 13948.

Alonso C, Medrano M, Pérez R, Canto A, Parra-Tabla V, Herrera CM. Interspecific variation across angiosperms in global DNA methylation: phylogeny, ecology and plant features in tropical and Mediterranean communities. New Phytol. 2019;224:949-60. https://doi.org/10.1111/nph.16046.

Australia Science Week. 2020. https://www.scienceweek.net.au/. Accessed 08 Jun 2020.

Auge GA, Leverett LD, Edwards BR, Donohue K. Adjusting phenotypes via within- and across generational plasticity. New Phytol. 2017;216:343-9. https://doi.org/10.1111/nph.14495.

Bloom P, Weisberg DS. Childhood origins of adult resistance to Science. Science. 2007;316:996-7. https://doi.org/10.1126/science.1133398.
British Science Week. 2020. https://www.britishscienceweek.org/. Accessed 08 Jun 2020.

Carey N. The epigenetics revolution: how modern biology is rewriting our understanding of genetics, disease and inheritance. Columbia University Press. 2012.

Erlich J, Zielinski D. DNA Fountain enables a robust and efficient storage architecture. Science. 2017;355(6328):950-4. https://doi.org/10.1126/ science.aaj2038.

Felsestein J. Theoretical Evolutionary Genetics. 2019. http://evolution.gs.washi ngton.edu/pgbook/pgbook.pdf. Accessed 27 Apr 2020.

Feria de la Ciencia. 2020. http://www.feriadelaciencia.org/. Accessed 08 Jun 2020.

Fredrickson BL, Branigan C. Positive emotions broaden the scope of attention and thought-action repertoires. Cogn Emot. 2005;19:313-32. https://doi. org/10.1080/02699930441000238.

Furrow RE, Hsu JL. Concept inventories as a resource for teaching evoIution. Evo Educ Outreach. 2019;12:2. https://doi.org/10.1186/ s12052-018-0092-8.

GENIE. Introduction to epigenetics. 2020. https://www2.le.ac.uk/projects/ vgec/highereducation/epigenetics_ethics/Introduction. Accessed 08 Jun 2020.

Hallam S. The power of music: its impact on the intellectual, social and personal development of children and young people. Int J Music Educ. 2010;28:269-89. https://doi.org/10.1177/0255761410370658.

Herrera CM, Bazaga P. Epigenetic correlates of plant phenotypic plasticity: DNA methylation differs between prickly and nonprickly leaves in heterophyllous Ilex aquifolium (Aquifoliaceae) trees. Bot J Linn Soc. 2013;171:441-52. https://doi.org/10.1111/boj.12007.

Hilker M, Schwachtje J, Baier M, et al. Priming and memory of stress responses in organisms lacking a nervous system. Biol Rev. 2016;91:1118-33. https://doi.org/10.1111/brv.12215.

Homburger SA, Drits-Esser D, Malone M, et al. Development and pilot testing of a three-dimensional, phenomenon-based unit that integrates evolution and heredity. Evo Educ Outreach. 2019;12:13. https://doi.org/10. 1186/s12052-019-0106-1.

Jablonka E. The evolutionary implications of epigenetic inheritance. Interface Focus. 2017;7:20160135. https://doi.org/10.1098/rsfs.2016.01352017.

Jablonka E, Raz G. Transgenerational epigenetic inheritance: prevalence, mechanisms, and implications for the study of Heredity and Evolution. Q Rev Biol. 2009;84(2):131-76. https://doi.org/10.1086/598822.

Kokko H, Chaturvedi A, Croll D, et al. Can Evolution supply what ecology demands? TREE. 2017;32(3):187-97. https://doi.org/10.1016/j.tree.2016. 12.005 .

Madrid Science Week. 2019. http://www.madrimasd.org/semanacienciaei nnovacion/. Accessed 08 Jun 2020.

Mead R, Hejmadi M, Hurst LD. Teaching genetics prior to teaching evolution improves evolution understanding but not acceptance. PLoS Biol. 2017;15(5):e2002255. https://doi.org/10.1371/journal.pbio.2002255.

MSCA-NIGHT. European Commission, Marie Skłodowska-Curie Actions: European Researchers' Night <https://ec.europa.eu/research/mariecurieactio ns/actions/european-researchers-night_en>. Accessed 27 Apr 2020.

Nicolaou CT, Evagorou M, Lymbouridou C. Elementary school students'emotions when exploring an authentic socio-scientific issue through the use of models. Sci Educ Inter. 2015;26(2):240-59.

Puig B, Jiménez-Aleixandre MP. Different Music to the Same Score: Teaching About Genes, Environment, and Human Performances. 2011; pp 201-238. TD Sadler (ed.), Socio-scientific Issues in the Classroom: Teaching, Learning and Research, Contemporary Trends and Issues in Science Education 39, https://doi.org/10.1007/978-94-007-1159-4_12

West Music. 2020. https://www.westmusic.com/b/boomwhackers/?count=22. Accessed 08 Jun 2020.

Woody S, Himelblau E. Understanding \& teaching genetics using analogies. Am Biol Teacher. 2013;75(9):664-9. https://doi.org/10.1525/abt.2013. 75.9.7.

\section{Publisher's Note}

Springer Nature remains neutral with regard to jurisdictional claims in published maps and institutional affiliations. 